\title{
Multiplex PCR for Rapid Diagnosis of Drug Resistant Mycobacterium Tuberculosis
}

\author{
Saira Salim1, Gohar Zaman1, Sidra Younis3, Wajid Hussain1, Umar Khurshid1 and Muhammad Tahir Khadim² \\ ${ }^{1}$ Department of Microbiology / Histopathology2, Armed Forces Institute of Pathology (AFIP), Rawalpindi, Pakistan \\ ${ }^{3}$ Department of Molecular Biology and Biochemistry, National University of Medical Sciences (NUMS), Rawalpindi, Pakistan
}

\begin{abstract}
Objective: To evaluate a multiplex PCR for rapid diagnosis of drug resistant mycobacterium tuberculosis (MTB) strain.

Study Design: Cross-sectional observational study.

Place and Duration of Study: Department of Microbiology, Armed Forces Institute of Pathology (AFIP), Rawalpindi, from January to September 2018.

Methodology: Over a period of 8 months, a total of 84 cultured positive samples were included in the study using nonprobability sampling techniques. MTB isolates were phenotypically characterised using MGIT 960 system for antituberculosis agents including rifampicin (RIF), isoniazid (INH), ethambutol (EMB) and Streptomycin. The DNA was extracted using Gentra system DNA extraction kit. The multiplex PCR was optimised for genetic characterisation of MTB samples for rpo B (rifampicin), kat G (isoniazid) and emb B (ethambutol) gene. The gel electrophoresis was performed to observe comparative banding pattern of amplified gene products.

Results: For detecting drug resistance, the specificity and sensitivity of multiplex PCR in isolates was $100 \%$ and $100 \%$ for rifampicin, $100 \%$ and $71 \%$ for isoniazid, and $100 \%$ and $60 \%$ for ethambutol, respectively. When compared to phenotypically resistance results, the positive predictive value (PPV) was $100 \%$ each and the negative predictive value (NPV) was calculated to be $100 \%, 74 \%$ and $71 \%$ for RIF, INH and EMB, respectively.

Conclusion: Multiplex PCR is a useful gadget for quick determination of drug-resistant TB in specimens, hence permitting an initial therapeutic approach. However, for accurate management of patients, phenotypic method should be used to confirm results.
\end{abstract}

Key Words: Multiplex PCR, Ethambutol, Rifampicin, Tuberculosis, Drug resistance.

How to cite this article: Salim S, Zaman G, Younis S, Hussain W, Khurshid U, Khadim MT. Multiplex PCR for Rapid Diagnosis of Drug Resistant Mycobacterium Tuberculosis. J Coll Physicians Surg Pak 2019; 29(9):833-7.

\section{INTRODUCTION}

Tuberculosis is one of the major global health problem due to evolution and spread of drug resistant MTB. ${ }^{1}$ According to WHO, Pakistan ranked fourth in MDR-TB. ${ }^{2}$ Success of TB control effort is highly dependent on rapid diagnosis and drug susceptibility determination of MTB strains. However, it takes weeks to get phenotypic results due to slow growth rate of bacteria. Nucleic acid amplification test (NAAT) are promising for a rapid diagnosis of DR-TB strains. ${ }^{3}$ The MTB strains are resistant to first line anti-TB drugs such as isoniazid (INH) and rifampicin (RIF) are denoted as MDR-MTB. 4 The MDR-MTB strains resistant to fluoroquinolones and any one of second line injectable agents, e.g. amikacin, kanamycin, capreomycine are XDR-MTB. ${ }^{5}$ Although various methods are available to diagnose MTB, ${ }^{6} \mathrm{ZN}$

Correspondence to: Dr. Saira Salim, Department of Microbiology, Armed Forces Institute of Pathology (AFIP), Rawalpindi,

Pakistan

E-mail: sairasalim2010@hotmail.com

Received: January 12, 2019; Revised: April 23, 2019;

Accepted: April 24, 2019 staining and culture that remains gold standard. The microscopy of acid fast bacilli by ZN staining is easy and simple. However, it is subjective and cannot detect MTB at low quantity. The gold standard of MTB is culture. It has high sensitivity but time consuming and requires further delay for susceptibility testing. ${ }^{7}$ The molecular methods are cost effective, rapid, and reliable with high sensitivity and specificity than phenotypic methods. ${ }^{8}$

Mutation in the rpo $B$ gene, that encodes the beta subunit of RNA polymerase, are responsible for rifampicin resistance. ${ }^{9}$ The mutations in kat $\mathrm{G}$, inh $A$, and ory $R$-ahpc genes accounts for the resistance against isoniazid. ${ }^{10}$ Ethambutol (EMB) inhibits arbinosyl transferees and mutation in emb $A$, emb $B$ and emb nce $C$ genes produce resistance against this agent. ${ }^{11}$ Furthermore, mutation in gyr $A$ and gyr $B$ genes confer resistance to fluoroquinolones. ${ }^{12,13}$ Molecular methods like PCR is cost effective with high sensitivity and specificity. Gene Xpert MTB/rifampicin assay has been endorsed by WHO for the diagnosis of pulmonary and extra pulmonary TB in endemic countries with $98 \%$ sensitivity and specificity. ${ }^{14,15}$ However, it detects resistance against rifampicin only. ${ }^{16}$ However, multiplex PCR differ from conventional PCR 
because we use multiple primer simultaneously to detect multiple MTB genes by setting optimum conditions in multiplex PCR. Therefore, in this study, the aim was to optimise a multiplex PCR method for diagnosis of mutations associate with resistance to $\mathrm{RIF}, \mathrm{INH}$ and EMB in DR-MTB cultured isolates.

\section{METHODOLOGY}

This study was conducted, Department of Microbiology, Armed Forces Institute of Pathology (AFIP), Rawalpindi, from January to September 2018. The study was ethically approved by Institutional Ethical Committee. A total of 84 samples were collected from MTB repository at AFIP. All smear positive pulmonary and extrapulmonary drug resistant MTB samples were included in the study. Anti-TB drug sensitive MTB samples were used as control. The repeated sample of same patient and mycobacterium other than tuberculosis (MOTS) were excluded. Smear positive specimens were treated before with standard sodium hydroxide-N-acetyl-Lcysteine method for decontamination, digestion, homogenisation and concentration. A smear was prepared and stained with Ziehl-Neelsen's stain. In this procedure, smear positive specimen was inoculated in BACTEC MGIT 960 system to culture MTB isolate. Culture media (7H9 broth, $7 \mathrm{~mL}$ ) was inoculated in barcoded mycobacterial growth indicator tube (MGIT). Growth supplement was added for enhancing growth of MTB and an antimicrobial mixture PANTA was added to MGIT tubes to suppress contamination. When an inoculated specimen yielded positive culture in MGIT system, we confirmed it by ZN staining and by MGIT 960 for TB identification test, which is a rapid chromatographic immunoassay for MTB antigen detection. Setting up for direct DST, lyophilized PANTA was reconstituted with $15 \mathrm{MI}$ of SIRE supplement (Becton Dickinson Diagnostic Systems, Sparks, MD) and mixed thoroughly. Lyophilized drugs (same as those used in MGIT) INH and RIF were reconstituted with $4 \mathrm{~mL}$ of sterile deionized (DI) water and mixed well.

A set of three MGIT tubes was prepared per specimen for performing the direct DST. One tube was labelled as $\mathrm{GC}$, one for INH and the other for RIF. PANTA-SIRE supplement mixture $(800 \mu \mathrm{L})$ was added in the labelled MGIT tubes. Then, the respective drugs were added in labelled tubes. The GC, INH and RIF tubes were placed in the set carrier and it was entered in the instrument. The first tube in the set carrier was always the GC tube. The growth unit (GU) value $\geq 400$ for $G C$ indicated the completion of test. Two hundred and fifty $\mu \mathrm{L}$ of cell lysis solution was added to the $1.5 / \mu \mathrm{L}$ eppendorf tube containing $50 / \mu \mathrm{L}$ of MTB culture isolates and incubated at $65^{\circ} \mathrm{C}$ for 15 minutes after thorough mixing with pipette.

After cell lysis, samples were cooled at the room temperature and then $100 / \mu \mathrm{L}$ protein precipitation solution was added to cell lysate followed by vortex. After protein precipitation step, the supernatant containing DNA was transferred carefully into eppendorf tube containing $250 / \mu$ isopropanol (100\%) and mixed by inversion. The samples were centrifuged again at $15000 \mathrm{~g}$ for 5 minutes. The supernatant was discarded and the pellet was washed with $70 \%$ ethanol and centrifuged at $15000 \mathrm{~g}$ for 15 minutes. The ethanol was removed without disturbing the DNA pellet using pipette. The pellet was dried by inverting tubes on absorbent paper followed by air dry for 15 minutes. The DNA pellet was hydrated in $10 \mu \mathrm{L}$ of DNA hydration solution and incubated at $65^{\circ} \mathrm{C}$ for 1 hour. The DNA samples were then stored at $-80^{\circ} \mathrm{C}$. Described primers were used to amplify rpo $B$, kat $G$ and emb $B$ genes as follow; 17,18 forward 5'- CGGCGATGAGCGTTACAC-3'and reverse 5'- CGTCCTTGGCGGTGTATT-3' for kat $G$ with 458bp PCR product, also forward 5'-CAGACGTTGATCAACATCCG3' and reverse 5- TACGGCGTTTCGATGAAC-3' for rpoB gene with 305bp PCR product forward primer for emb $B$ gene was 5'- GGATGCCGTTCAACAACGG-3' and reverse 5'- CGCGAACCCTGGTGGCTTC-3' with 306bp PCR product.

Multiplex PCR were optimised and done in a final volume of $27 \mu \mathrm{l}$ for the amplification of the rpo $B$, kat $G$ and emb $B$ genes as mentioned in Table II. The thermo cycler programme of PCR reaction mixture was including an initial denaturation step of 5 minutes at $95^{\circ} \mathrm{C} ; 40$ cycles of 30 seconds at $95^{\circ} \mathrm{C}, 30$ seconds at annealing temperature of $57^{\circ} \mathrm{C}$ and 45 seconds at $72^{\circ} \mathrm{C}$ and final extension step at $72^{\circ} \mathrm{C}$ for seven minutes. The PCR amplified product was separated on $1 \%$ agarose gel and visualised under ultraviolet light.

Results were subjected for statistical analysis on SPSS version 24. Descriptive statistics including sensitivity, specificity, negative predictive value, positive predictive value and diagnostic accuracy of phenotypically resistant isolates of MTB and drug sensitive samples as a negative control for multiplex PCR.

\section{RESULTS}

Among 84 MTB isolates, MGIT culture method detected $18(21 \%)$ isolates as MDR, and $66(79 \%)$ as single drug resistant including 17 (20\%) RIF resistant, 39 (47\%) INH resistant and $10(12 \%)$ EMB resistant isolates. Out of the 18 MDR MGIT culture positive isolates, only $9(50 \%)$ showed all two mutated bands on multiplex PCR. Moreover, among single drug-resistant, i.e. 17 RIF, 39 INH and 10 EMB MGIT culture positive isolates, mutated bands were detected in $17(100 \%)$ of $r p o ~ B$ gene for RIF, $28(71 \%)$ of $k a t G$ gene for INH and $6(60 \%)$ of emb $B$ gene for EMB in multiplex PCR. The characteristic banding pattern obtained by using the multiplex PCR for RIF, INH and EMB resistant isolates is shown in Figures 1 and 2. Sensitivity, specificity, positive predictive value, negative predictive value, diagnostic accuracy of 
Table I: The primers and PCR conditions for genotypic characterisation of MTB samples.

\begin{tabular}{l|l|l|l|l}
\hline Anti-TB drugs & Targets site & Primers & Ref & PS \\
\hline Rifampicin & rop B (531) & $\begin{array}{l}\text { F: CAGACGTTGATCAACATCCG } \\
\text { R: TACGGCGTTTCGATGAAC }\end{array}$ & 57 \\
\hline Isoniazid & kat G (315) & $\begin{array}{l}\text { F: CGGCGATGAGCGTTACAC } \\
\text { R: CGTCCTTGGCGGTGTATT }\end{array}$ & 57 \\
\hline Ethambutol & emb B (345) & $\begin{array}{l}\text { F: GGATGCCGTTCAACAACGG } \\
\text { R: CGCGAACCCTGGTGGCTTC }\end{array}$ & 458 \\
\hline
\end{tabular}

$T m=$ Temperature; $P S$ = Product size; Ref $=$ Reference

Table II: Multiplex PCR reaction mixture.

\begin{tabular}{l|l|l}
\hline Reagents & Concentration & Volume \\
\hline Distilled water & & $16.1 \mu \mathrm{l}$ \\
Forward primers for rpo B, kat G and em B genes & $1 \mu \mathrm{M}$ & $3 \mu \mathrm{l}$ \\
Reverse primers for rpo B, kat G and emb B genes & $1 \mu \mathrm{M}$ & $3 \mu \mathrm{l}$ \\
Magnesium chloride (MgC12) & $2.5 \mu \mathrm{M}$ & $2.5 \mu \mathrm{l}$ \\
Buffer without MgC12 & $2 \mu \mathrm{M}$ & $2 \mu \mathrm{l}$ \\
dNTPS & $0.5 \mu \mathrm{M}$ & $0.5 \mu \mathrm{l}$ \\
Taq polymerase & $0.5 \mu \mathrm{M}$ & $0.5 \mu \mathrm{l}$ \\
DNA & $1-5 \mathrm{ng}$ & $1.4 \mu \mathrm{l}$ \\
\hline Total & $1-5 \mathrm{ng}$ & $25-27 \mu \mathrm{l}$ \\
\hline
\end{tabular}

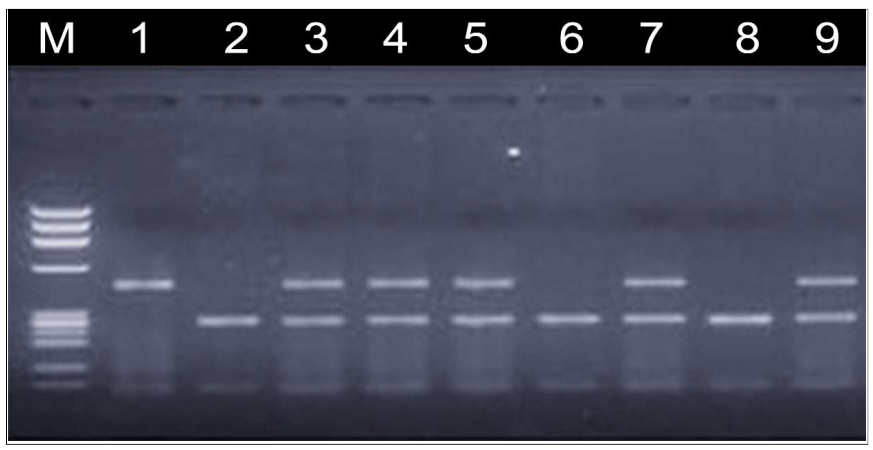

Figure 1: Characteristic banding pattern obtained for single and multiple drug resistant strains using multiplex PCR.

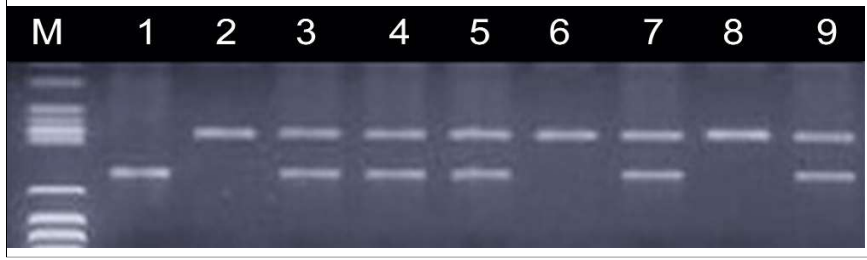

Figure 2: Characteristic banding pattern obtained for EMB resistant strain using multiplex PCR. multiplex PCR taking MGIT culture system as gold standard are shown in Table III.

A characteristic ethidium bromide stained $1 \%$ agarose gel displaying banding pattern obtained after multiplex PCR containing primer pairs for RIF (rpoB), INH (katG) and EMB (embB) gene. A single band of $305 \mathrm{bp}$ specifies resistance to RIF. A single band of $458 \mathrm{bp}$ specifies resistance to $\mathrm{INH}$. A single band of $306 \mathrm{bp}$ specifies resistance to EMB. Two bands of $305 \mathrm{bp}$ and $458 \mathrm{bp}$ specify the resistance to RIF and INH. Two bands of $306 \mathrm{bp}$ and $458 \mathrm{bp}$ specify the resistance to EMB and $\mathrm{INH}$, respectively. Lane M: 100bp DNA ladder, Lane 1: SDR (INH), Lane 2, 6 and 8: SDR (RIF), Lane 3-5, 7 and 9: MDR (RIF and INH).

A characteristic ethidium bromide stained $1 \%$ agarose gel displaying banding pattern obtained after multiplex PCR containing primer pairs for RIF (rpoB), INH (katG) and EMB (embB) gene. A single band of $305 \mathrm{bp}$ specifies resistance to RIF. A single band of $458 \mathrm{bp}$ specifies resistance to $\mathrm{INH}$. A single band of $306 \mathrm{bp}$ specifies resistance to EMB. Two bands of $305 \mathrm{bp}$ and $458 \mathrm{bp}$ specify the resistance to RIF and INH. Two bands of $306 \mathrm{bp}$ and $458 \mathrm{bp}$ specify the resistance to EMB and $\mathrm{INH}$, respectively. Lane M: 100 bp DNA ladder, Lane 1: SDR (EMB).

\section{DISCUSSION}

In the present research, authors evaluated a multiplex PCR that allowed simultaneous detection of MTB resistance to RIF, INH and EMB in 84 MTB resistant isolates. Selected primers were for three loci at which RIF, INH and EMB resistance associated mutation for rpo $B$ (531), kat $G$ (316), and emb $B$ gene (345) were most frequently observed.

Table III: Comparison of sensitivity, specificity, NPV, PPV and DA between phenotype and genotype-based characterisation of drug resistant MTB isolates.

\begin{tabular}{|c|c|c|c|c|c|c|c|c|}
\hline \multirow[t]{2}{*}{ Resistance pattern } & \multirow[t]{2}{*}{ Mutiple PCR } & \multicolumn{2}{|c|}{ Culture } & \multirow[t]{2}{*}{ Sensitivity } & \multirow[t]{2}{*}{ Specificity (\%) } & \multirow[t]{2}{*}{ PPV (\%) } & \multirow[t]{2}{*}{ NPV (\%) } & \multirow[t]{2}{*}{$\mathrm{DA}(\%)$} \\
\hline & & $\mathrm{R}$ & $S$ & & & & & \\
\hline \multirow[t]{2}{*}{ MDR } & $\mathrm{R}$ & 9 & 0 & \multirow[t]{2}{*}{50} & \multirow[t]{2}{*}{100} & \multirow[t]{2}{*}{100} & \multirow[t]{2}{*}{33} & \multirow[t]{2}{*}{59} \\
\hline & $S$ & 9 & 4 & & & & & \\
\hline \multirow[t]{2}{*}{ RIF } & $\mathrm{R}$ & 17 & 0 & \multirow[t]{2}{*}{100} & \multirow[t]{2}{*}{100} & \multirow[t]{2}{*}{100} & \multirow[t]{2}{*}{0} & \multirow[t]{2}{*}{100} \\
\hline & $S$ & 0 & 4 & & & & & \\
\hline \multirow[t]{2}{*}{$\mathrm{INH}$} & $R$ & 28 & 0 & \multirow[t]{2}{*}{71} & \multirow[t]{2}{*}{100} & \multirow[t]{2}{*}{100} & \multirow[t]{2}{*}{26} & \multirow[t]{2}{*}{74} \\
\hline & $S$ & 11 & 4 & & & & & \\
\hline \multirow[t]{2}{*}{ EMB } & $\mathrm{R}$ & 6 & 0 & \multirow[t]{2}{*}{60} & \multirow[t]{2}{*}{100} & \multirow[t]{2}{*}{100} & \multirow[t]{2}{*}{50} & \multirow[t]{2}{*}{71} \\
\hline & $S$ & 4 & 4 & & & & & \\
\hline
\end{tabular}


Sensitivity of multiplex PCR for detection of rifampicin resistance varies from region to region. In this study, sensitivity and specificity was found to be $100 \%$ comparable to similar study conducted in China with sensitivity of $81.5 \%$ and specificity of $92 \%$ for RIF. ${ }^{19}$ One national study conducted in the Aga Khan Hospital, Karachi that compared phenotypic with genotypic molecular test (line probe assay PCR) with sensitivity $92.5 \%$ and specificity of $98.2 \%$ for RIF. 20

It has been well established that most INH-resistant isolates possess mutation in kat $G$ or inh $A$ or both. ${ }^{21}$ In this study, the most prevalent mutation at 458 bp region of kat $\mathrm{G}$ encompassing codon 315 was used. The total of $39 \mathrm{INH}$ resistant isolates were identified in MGIT 960, $28(42 \%)$ of which were found to contain mutation in kat $G$. In contrast, the remaining $11(17 \%)$ had no mutation within 315 , the target fragment of kat $G$ gene. The sensitivity and specificity for kat $G$ gene in this study was $71 \%$ and $100 \%$, respectively. Similar study conducted in China with sensitivity and specificity of $41 \%$ and $100 \%$ for isoniazid resistant kat $G$ gene. ${ }^{17}$

In this study, 306bp region of emb $B$ gene for ethambutol was used. Out of $10 \mathrm{EMB}$ resistant isolates identified in MGIT 960 system, 6 (10\%) showed mutated bands in multiplex PCR for emb $B$ gene. The sensitivity and specificity was $60 \%$ and $100 \%$, respectively in this study. Very few reports have evaluated this emb $B$ gene using MGIT system and multiplex PCR. However, this study evaluates emb $B$ gene for ethambutol resistant as well.

In this study, simultaneous detection of MDR for kat $G$ and rpo $B$ was used. Out of the 18 MDR isolates identified in MGIT 960 system, 11 (14\%) showed mutated bands in multiplex PCR, with sensitivity and specificity of $50 \%$ and $100 \%$ respectively in multiplex PCR. A similar study conducted for MDR showed sensitivity and specificity of $34 \%$ and $99 \%$, respectively. ${ }^{17}$

In this study, out of total 84 isolates, $66(79 \%)$ isolates had concordant results on both the methods (culture phenotypic method) or genotypic (multiplex PCR tests). Individually, INH had $38 \%$ while RIF had $17 \%$ concordance. The results of this study are similar to study by Ali et al. in which there was $84 \%$ concordance for INH and $100 \%$ for RIF. 17

The main focus of this study was time-saving by multiplex PCR when compared with culture. Overall time-saving by multiplex PCR in our study was 8 to 13 days. This time saving is very important as it can help the clinicians in initiation of early therapy and thus controlling the spread of drug resistant tuberculosis (MDR or XDR) isolates.

This study has two main limitations. First, it was carried out on smear positive specimens only. Secondly, it was single-centre study and the representation of MDR isolates was small i.e. $21 \%$ of the total isolates.

\section{CONCLUSION}

Multiplex PCR is useful gadget for quick determination of drug resistant TB in specimens, hence permitting an initial therapeutic approach. However, for accurate management of patients, phenotypic method should be used to confirm results.

\section{ETHICAL APPROVAL:}

The study was ethically approved by Institutional Ethical Committee

\section{CONFLICT OF INTEREST:}

Authors declared no conflict of interest.

\section{AUTHORS' CONTRIBUTION:}

SS, GZ: Did the project.

SY: Concept.

WH, UK: Peer viewed written stuff.

TK: Provided sources for research.

\section{REFERENCES}

1. Falzon D, Schünemann HJ, Harausz E, González-Angulo L, Lienhardt C, Jaramillo E, et al. World Health Organization treatment guidelines for drug-resistant tuberculosis, 2016 update. Eur Respir J 2017; 49:1602308.

2. Glaziou P, Floyd K, Raviglione MC, editors. Global epidemiology of tuberculosis. Seminars in respiratory and critical care medicine; 2018: Thieme Medical Publishers.

3. Zhao LI, Xia Q, Lin N, Liu Z-g, Zhao XQ, Wan KI. Multiplex allele-specific PCR combined with PCR-RFLP analysis for rapid detection of gyrA gene fluoroquinolone resistance mutations in mycobacterium tuberculosis. J Microbiol Methods 2012; 88:175-8.

4. Gandhi NR, Nunn P, Dheda K, Schaaf HS, Zignol M, Van Soolingen $\mathrm{D}$, et al. Multidrug-resistant and extensively drugresistant tuberculosis: A threat to global control of tuberculosis. Lancet 2010; 375:1830-43.

5. Zignol M, Gemert Wv, Falzon D, Sismanidis C, Glaziou P, Floyd $\mathrm{K}$, et al. Surveillance of anti-tuberculosis drug resistance in the world: An updated analysis, 2007-2010. Bulletin of the World Health Organization 2012; 90:111-9.

6. Sankar MM, Singh J, Diana SCA, Singh S. Molecular characterization of Mycobacterium tuberculosis isolates from North Indian patients with extrapulmonary tuberculosis. Tuberculosis 2013; 93:75-83.

7. Drobniewski F, Rüsch-Gerdes S, Hoffner S. Antimicrobial susceptibility testing of mycobacterium tuberculosis (EUCAST document $E$. def 8.1)-report of the subcommittee on antimicrobial susceptibility testing of mycobacterium tuberculosis of the European Committee for antimicrobial susceptibility testing (EUCAST) of the European society of clinical microbiology and infectious diseases (ESCMID). Clin Microbiol Infect 2007; 13:1144-56.

8 Patel R, Fries J, Piessens W, Wirth D. Sequence analysis and amplification by polymerase chain reaction of a cloned DNA fragment for identification of mycobacterium tuberculosis. J Clin Microbiol 1990; 28:513-8.

9. Telenti A, Honore N, Bernasconi Ca, March J, Ortega A, Heym B, et al. Genotypic assessment of isoniazid and rifampin 
resistance in mycobacterium tuberculosis: A blind study at reference laboratory level. J Clin Microbiol 1997; 35:719-23.

10. Sreevatsan S, Pan X, Zhang Y, Deretic V, Musser JM. Analysis of the oxyR-ahpC region in isoniazid-resistant and-susceptible mycobacterium tuberculosis complex organisms recovered from diseased humans and animals in diverse localities. Antimicrob Agents Chemother 1997; 41:600-6.

11. Köser CU, Bryant JM, Becq J, Török ME, Ellington MJ, MartiRenom MA, et al. Whole-genome sequencing for rapid susceptibility testing of M. tuberculosis. N Engl J Med 2013; 369:290-2.

12. Eilertson B, Maruri F, Blackman A, Herrera M, Samuels DC, Sterling TR. High proportion of hetero-resistance in gyrA and gyrB in fluoroquinolone resistant mycobacterium tuberculosis clinical isolates. Antimicrob Agents Chemother 2014; 58:3270-5.

13. Maruri F, Sterling TR, Kaiga AW, Blackman A, van der Heijden YF, Mayer $\mathrm{C}$, et al. A systematic review of gyrase mutations associated with fluoroquinolone-resistant mycobacterium tuberculosis and a proposed gyrase numbering system. J Antimicrob Chemother 2012; 67:819-31.

14. Steingart KR, Sohn H, Schiller I, Kloda LA, Boehme CC, Pai M, et al. Xpert ${ }^{\circledR}$ MTB/RIF assay for pulmonary tuberculosis and rifampicin resistance in adults. Cochrane Database Syst Rev 2014; 1:CD009593.

15. Zeka AN, Tasbakan S, Cavusoglu C. Evaluation of the GeneXpert MTB/RIF assay for the rapid diagnosis of tuberculosis and detection of RIF-resistance in pulmonary and extrapulmonary specimens. J Clin Microbiol 2011; 49:4138-41.
16. Chakravorty S, Simmons A, Rowneki M, Parmar H, Cao Y, Ryan J, et al. The new Xpert MTB/RIF ultra: Improving detection of mycobacterium tuberculosis and resistance to rifampin in an assay suitable for point-of-care testing. MBio 2017; 8:e00812-17.

17. Ali IFA, Babak F, Fazlollah MS, Nematollah JJ. Rapid detection of MDR-mycobacterium tuberculosis using modified PCRSSCP from clinical specimens. Asian Pac J Trop Biomed 2014; 4(Suppl 1):S165-70.

18. Moure R, Español M, Tudó G, Vicente E, Coll P, GonzalezMartin $\mathrm{J}$, et al. Characterization of the embB gene in mycobacterium tuberculosis isolates from Barcelona and rapid detection of main mutations related to ethambutol resistance using a low-density DNA array. J Antimicrob Chemother 2014; 69:947-54.

19. Cheng X, Zhang J, Yang L, Xu X, Liu J, Yu W, et al. A new multiPCR-SSCP assay for simultaneous detection of isoniazid and rifampin resistance in mycobacterium tuberculosis. J Microbiol Methods 2007; 70:301-5.

20. Farooqi JQ, Khan E, Alam SMZ, Ali A, Hasan Z, Hasan R. Line probe assay for detection of rifampicin and isoniazid resistant tuberculosis in Pakistan. J Pak Med Assoc 2012; 62:767-72.

21. Campbell PJ, Morlock GP, Sikes RD, Dalton TL, Metchock B, Starks AM, et al. Molecular detection of mutations associated with first- and second-line drug resistance compared with conventional drug susceptibility testing of mycobacterium tuberculosis. Antimicrob Agents Chemother 2011; 55:2032-41. 